\title{
Trauma in surgery and its incidence, circumstances as well as clinical consequences
}

\author{
Faruquzzaman ${ }^{1}$, Moniruzzaman $\mathrm{M}^{2}$, Mohiuddin $\mathrm{T}^{3}$ \\ Chittagong Medical College Hospital, Chittagong, Bangladesh.drfaruquzzaman@yahoo.com
}

\begin{abstract}
This study was conducted from 10.02 .08 to 23.05.09 in general surgery wards of Chittagong Medical College Hospital, Bangladesh with multi-factorial views of clinical aspects and an alarming model image in such relation was depicted. $188(72.9 \%)$ patients in this study out of 258 were male it was and found that different types of trauma had been relatively higher in 51-70 yrs (35.1\%) age group followed by $31-50 \mathrm{yrs}(28.7 \%)$ age group in case of male subjects. On the contrary, in female, those were quite higher in 11-30 yrs (31.4\%) age group followed by $51-70$ yrs $(24.8 \%)$ age group. As for the mortality, this study suggest that it was significantly higher in case of female subjects (31.4\%) (22) in relation to male subjects (18.1\%) (34). But to our knowledge probably it has no clinical significance at all. Rather, it may have socio-economic associations, as for instancetraditional negligence to female in developing countries like Bangladesh. Another remarkable observation that was clear in this study was variation in different levels of morbidity. In male, $30.9 \%$ patients had morbidity from 1 week to 1 month; followed by $28.7 \%$ patients with morbidity less than 1 week, whereas, in case of female, it was $25.7 \%$ and $20 \%$, respectively. With regard to morbidity over 1 month $23.4 \%$ male and $22.9 \%$ female were found in this group and in case of both male and female, the so called p-values were quite significant. This study also reflects that majority of trauma occurred due to road traffic accidents (RTAs) $(24.5 \%)$ followed by natural disasters $(21.3 \%)$ and assault (17\%) in case of male, whereas, in female $34.3 \%$ trauma occurred by assault and homicidal attempts followed by $20 \%$ due to natural disaster. One of the most remarkable associations of traumatic patients was that $82.3 \%$ (28) of all deaths occurred in the first 24 hours of injury in male and on the other hand, it was $72.7 \%$ (16) in case of female patients (Tab. 3, Fig. 7, Ref. 31). Full Text in free PDF www.bmj.sk. Key words: trauma, surgery, death, homicidal attempts, natural disaster.
\end{abstract}

Trauma was estimated to have caused $10 \%$ of all deaths occurring in 1990 world-wide (1). Truly, it may be described as an epidemic. The details of this epidemic differ according to location. The causes of traumatic death in the developed world are different to those in the developing world. Nonetheless, trauma remains the third leading cause of death in all regions of the world, regardless of these differences (2). If only young people are considered, trauma becomes the leading cause of death and is thus the greatest source of potential years of life lost (3).

It is well recognized that for every death due to injury, there are many more people who are left disabled. For each of the 165000 trauma deaths in the United States of America in 1982, there were

${ }^{1}$ Chittagong Medical College Hospital Chittagong, Bangladesh, ${ }^{2}$ Union Health Sub-centre, Barakpur, Khulna, Bangladesh, and ${ }^{3}$ Sher-e-Bangla Medical College Hospital, Barisal, Bangladesh

Address for correspondence: Faruquzzaman, Dr, Moazzem Hossain House No. 7, Islambay Road (Paulpara) Railygate, Daulatpur P. code 9202, Bangladesh.

Phone: +8801713312349

Acknowledgement: I am highly grateful to my respected teacher, Prof. DR. SAROJ KUMAR MAZUMDER, the honorable head of the Department of Community Medicine, Chittagong Medical College, Bangladesh, and MD Moazzen Hossain, Ex-Engineer of Roads And High Ways Department of Bangladesh Governments for their kind permission, support and help especially financial for conducting this study and also thankful to the respondents who gave their valuable time to enhance the study. at least two cases of permanent disability (3). The Global Burden of Disease Study developed the concept of Disability Adjusted Life Years (DALYs). It was calculated that in 1990, intentional and unintentional injuries caused $10 \%$ of mortality world-wide, but $15 \%$ of DALYs (4). Changing demographics have an influence on patterns of injury. The population of the world is still increasing earlier this year it reached 6 billion. However, the rate of population growth has been steadily slowing for the past 20 years. Between 1990 and 1994, the annual growth rate fell to $1.57 \%$, but again, there is a marked difference between the rates in developed and developing countries. In the developing world between 1990 and 1995 , the population growth rate was $2.8 \%$ per annum, compared to $0.4 \%$ in the industrialized nations. 5 Throughout the world, birth rates are falling and life expectancy is improving.

In addition, the world is becoming more urbanized. In 1975, 38 $\%$ of the total population lived in urban areas, but by 1988 this had increased to $42 \%$. By the year 2000 , it is predicted that $47 \%$ of the world's population will be living in cities (5). The net effect of these changes is to produce a population with a smaller proportion of young people, a greater proportion of the elderly, and a growing proportion of people living in cities. This, in turn, affects patterns of injury around the world, although the relationship between increasing urbanization and injury rates is far from straightforward. It has been claimed that the recent decrease in homicides in the USA can be attributed, in part, to the diminishing number of young men 
(6). Meanwhile, the enlarging elderly population is more likely to have domestic accidents and to be more severely injured in any accident. Another influential factor affecting patterns of injury all over the world is the increasing use of alcohol and other drugs. In one study, about $50 \%$ of people dying from injury tested positive for blood alcohol (7). Some $56 \%$ of all the trauma admissions to the orthopaedic department of a New Orleans hospital during 1993 and 1994 tested positive for drugs or alcohol, rising to $71 \%$ of those admitted with gunshot wounds (8). In the UK, the Department of Transport estimated that in the 11 months before October 1996, $25 \%$ of road fatalities had taken drugs, $20 \%$ of which were illicit substances (9). A pedestrian who has been drinking is two-anda-half times more likely to be involved in a road traffic accident (RTA) than one who has not (10). Despite this undoubted association, the involvement of alcohol and other drugs in homicides, assaults and suicides is extremely complex, and is associated with other factors such as mental or physical illness, deviant personality types, poverty and cultural acceptance of violence.

Alcohol consumption has certainly increased during the past three decades, particularly in the developing countries. In the developed world, however, there is some evidence that increased public awareness has led to safer behaviour patterns. Stinson and De Bakey11 found that alcohol-related deaths in the USA actually fell during the 1980 s, largely due to an improvement in the drink-driving figures.

\section{Increase in alcohol consumption during 1960-1981 (12):}

- Canada $95 \%$

- Japan $169 \%$

- The Netherlands $243 \%$

- Korea $762 \%$

During the past 20 years, motor vehicle density has increased everywhere. For example, between 1976 and 1994, the number of cars in the UK increased from nearly 18 million to 25 million. In the USA, the rise over the same period was from 142 to 202 million, while in Japan, the number of cars per thousand population increased by $426 \%$ between 1970 and 1994 (13).

In developed countries, the past 20 years have seen increased legislation and public effort with regard to seat belts, motor-cycle helmets, airbags, speed limits and drink driving campaigns. These initiatives appear to be paying off. In the UK in 1977, young men between the ages of 15 and 24 years suffered a mortality rate of 605 deaths per million as a result of trauma, with $65 \%$ of these deaths being due to road accidents. By 1992 in the same age group, not only had the number of deaths resulting from trauma fallen to 487 per million, but only $46 \%$ of these were caused by RTAs (14). On the whole, this is reflected in other developed countries around the world. The repeal of safety legislation, as has happened from time to time in the USA and elsewhere, reverses this trend. In the USA, this reduction in mortality from road deaths has been leveling off for the past four years and mortality, in fact, started to rise again in the late 1990s. In 1995, traffic accidents superseded guns as the leading cause of death among children and young adults. The abolition of the nation-wide $55 \mathrm{mph}$ speed limit last year may blacken the picture further (5).
Currently, numbers of suicides are increasing, and there are few countries where this is an exception. In many established market economies where the rate of road deaths is decreasing and the homicide rate is at least stable, suicides are forming a larger proportion of violent deaths. This would appear to parallel the large increase in mental illness, and particularly unipolar depression, reported by the World Health Organization (WHO) during the past decade. Between $60 \%$ and $80 \%$ of suicides are associated with depression (15). Some facts about suicide remain constant over time and place. More men commit suicide than women, the ratio being at least 3:1 (often much higher). More older people commit suicide than younger people, with people aged over 75 years having a suicide rate about three times that of younger groups. Nonetheless, suicide has been one of the top five causes of death for the 15- to 24-year age group for many years, and the number is still increasing (15). Generally, suicide is under-reported, perhaps because it often goes unrecognized. Many road fatalities among young male pedestrians may be suicides rather than accidents. Sometimes, however, there is a reluctance to classify deaths as suicides. For example, in Roman Catholic countries, where suicide is regarded as a mortal sin by the Church, many such deaths are classified as accidental or of undetermined cause. Greece, Italy and Spain have among the lowest suicide rates in Europe (15). The USA and Europe has shown a general increase in suicide over the last three decades, particularly among 15- to 24-yearold men. There are one or two exceptions to this. For example, Hungary has had one of the highest suicide rates in the world for many years, but among Hungarian adolescents and young adults the rate has actually decreased slightly over the past 35 years. The UK has experienced the same increase in young suicides as the rest of Europe, but is the only country to record a fall in the suicide rate among the over- 75 s during the last 35 years. ${ }^{15}$ With few exceptions, the level of homicide in developed countries over the last two decades has shown little change (16). The USA is unusual in that it is an established market economy with a relatively high homicide rate. Between 1975 and 1992, the overall annual male homicide rate remained steady at about 16 per 100000 population, yet at the same time the rate for 15- to 24-year old men rose from 21 to 37 per 100000 population $(17,18)$. However, in the last decade the rates appear to be stabilizing. The National Center for Health Statistics reports firearm death rates reaching a peak of 15.6 per 100000 in 1993 , and then falling to 13.9 per 100000 in 1995 , a decrease of $11 \%$. This fall in fatal shootings is variously attributed to stricter laws and their enforcement, changes in public attitudes, and the fact that there are now fewer young men in the highest risk age group (6).

Between $20 \%$ and $30 \%$ of all accidental deaths occur in the home $(19,20)$. For every death, there may be as many as four cases of permanent impairment (20). The two age groups particularly at risk of domestic injury are children over the age of 1 year and adults over 65 years (21). However, the elderly have a far higher mortality rate than the young; for example, in the UK, 12-13\% of all domestic accidents occur in the over- 65 age group, but these people suffer at least $70 \%$ of domestic deaths (22). Children may have most of their accidents at home, but motor vehicles cause 
most of their deaths (23). The 15- to 64-year-old age group suffer far fewer domestic accidents and deaths. Overdoses cause about one-half of the deaths, and of the remainder the majority can be ascribed to falls and fires. Alcohol/drug use is involved in $71 \%$ of domestic deaths in this age group (24).

In the UK, the annual fatal injury incidence rate has been declining for many years. It is currently well under 2 per 100000 employees, which is less than half the rate of the early 1970s and less than one-quarter of the rate of the early 1960s. A large proportion of this change is probably because of the demographic changes mentioned (25). However, it is also felt that there have been significant improvements in safety standards in many industries (26). Over the past 10 years, the most frequent causes of death across industry as a whole have remained falling from a height, and being struck by a moving vehicle. In the UK, the annual fatal injury incidence rate has been declining for many years. It is currently well under 2 per 100000 employees, which is less than half the rate of the early 1970s and less than one-quarter of the rate of the early 1960s. A large proportion of this change is probably because of the demographic changes mentioned (25). However, it is also felt that there have been significant improvements in safety standards in many industries (26). Over the past 10 years, the most frequent causes of death across industry as a whole have remained falling from a height, and being struck by a moving vehicle (31).

Male deaths per 100000 population from accidents caused by machinery $(18,27-30)$.

\begin{tabular}{lcc}
\hline & 1979 & 1992 \\
\hline USA & 1.5 & 0.9 \\
Australia & 1.2 & 0.8 \\
The Netherlands & 0.7 & 0.4 \\
England/Wales & 0.7 & 0.4 \\
\hline Source: Refs $18,27-30$ & &
\end{tabular}

\section{Methods and materials}

1. Type of study: Descriptive type of epidemiological cross-sectional study.

2. Place of study: The general surgery indoor department (Unit 1 and 2) of Khulna Medical college Hospital, Bangladesh.

3. Period of study: From 10.02.08 to 23.05.09

4. Study population: Patients, admitting in the general surgery indoor department of Khulna Medical College Hospital, Bangladesh.

\section{Sample size: 284}

The sample size was selected by using the formula $Z^{2} \mathrm{pq} \times D$

Where, $Z=$ Given confidence level. $(Z=1.96$ for $95 \%$ confidence level)

$\mathrm{p}=$ Probability $=20 \%=0.20$

$\mathrm{q}=1.0-\mathrm{p}=0.8\left(\mathrm{C}_{1}-\mathrm{p}\right)$

Degree of error limit (the accuracy desired)

6. Sampling technique: Convenient type of purposive sampling.

7. Data collection instruments: a) By preparing questionnaires. b)

By direct observation. c) By active participation.

8. Data collection period: From 10.02.08 to 12.05.09

9. Methods of data collection: a) By interviewing through questionnaires. b) By direct observation.
10. Data analysis: After collection, data were checked, verified, compared, reviewed and analyzed according to the objectives and purposes of the study.

Using computer based statistical package statistical analysis of the data was done. Data were analyzed with SPSS computer package programme. The survey data was usually analyzed using descriptive statistic. Such as; mean, SD, percentage, co-efficient of variation.

Report was produced by computer based programme- Microsoft Word, Power point, Photoshop, Adobe and other accessories.

\section{Results and discussion}

The relevant associations of this study conducted from 10.02.08 to 23.05.09 in general surgery wards of Chittagong Medical College Hospital, Bangladesh were as follows:

$188(72.9 \%)$ patients in this study out of 258 were male in sex (Fig. 1) and the total age distribution in relation to sex is shown in (Tab. 1).

Table 1 suggests that different types of trauma were relatively higher in 51-70 yrs $(35.1 \%)$ age group followed by 31-50 yrs $(28.7 \%)$ age group in case of males. On the contrary, in females, those were quite higher in 11-30 yrs (31.4\%) age group followed by $51-70$ yrs $(24.8 \%)$ age group.

In the question of mortality, this study suggest that it was significantly higher in case of females $(31.4 \%)(22)$ in relation to males (18.1\%) (34) (Fig. 2). But to our mind, probably it had no clinical significance at all. Rather, it may have socio-economic

Tab. 1. Distribution of different types of trauma in relation to age and sex.

\begin{tabular}{lll}
\hline Age group in year & Male & Female \\
\hline$\leq 10$ & 16 & 6 \\
$\%$ & 8.5 & 8.6 \\
$11-30$ & 32 & 22 \\
$\%$ & 17 & 31.4 \\
$31-50$ & 54 & 13 \\
$\%$ & 28.7 & 18.6 \\
$51-70$ & 66 & 17 \\
$\%$ & 35.1 & 24.8 \\
$>70$ & 20 & 12 \\
$\%$ & 10.6 & 17.1 \\
\hline
\end{tabular}

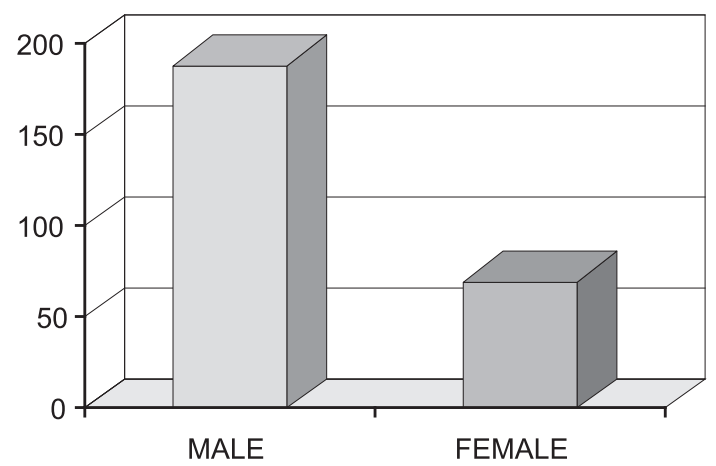

Figure 1. 
Tab. 2. Different levels of morbidity.

\begin{tabular}{lcccc}
\hline Sex & $\begin{array}{c}\text { Less than } \\
1 \text { week }\end{array}$ & $\begin{array}{c}\text { 1 week to } \\
1 \text { month }\end{array}$ & $\begin{array}{c}\text { Over } \\
\text { 1 month }\end{array}$ & p-values \\
\hline Male & & & & 0.05 \\
$\leq 10$ & 2 & 6 & 4 & \\
$11-30$ & 12 & 10 & 8 & \\
$31-50$ & 16 & 16 & 10 & \\
$51-70$ & 20 & 20 & 14 & \\
$>70$ & 4 & 6 & 8 & \\
\hline Total & 54 & 58 & 44 & \\
$\%$ & 28.7 & 30.9 & 23.4 & \\
\hline & & & & \\
Female & & & & \\
$\leq 10$ & 2 & 51 & & \\
$11-30$ & 5 & 7 & 3 & \\
$31-50$ & 3 & 3 & 3 & \\
$51-70$ & 2 & 5 & 4 & \\
$>70$ & 2 & 2 & 22.9 & \\
\hline Total & 14 & 18 & & \\
$\%$ & 20 & 25.7 & & \\
\hline
\end{tabular}

Tab. 3. Table 3 suggests the most common causes of trauma in both sexes.

\begin{tabular}{llcc}
\hline Causes & Male & Female & p-values \\
\hline RTAs & 46 & 8 & 0.01 \\
$\%$ & 24.5 & 11.4 & \\
Assault and homicidal & 32 & 24 & \\
$\%$ & 17 & 34.3 & \\
Suicidal & 8 & 10 & \\
$\%$ & 4.2 & 14.3 & \\
Domestic deaths & 6 & 6 & \\
$\%$ & 3.1 & 8.5 & \\
Occupational injuries & 24 & 4 & \\
$\%$ & 12.8 & 5.7 & \\
Natural disasters & 40 & 14 & \\
$\%$ & 21.3 & 20 & \\
War & 0 & 0 & \\
$\%$ & 0 & 0 & \\
Others & 32 & 4 & \\
$\%$ & 17 & 5.7 & \\
\hline
\end{tabular}

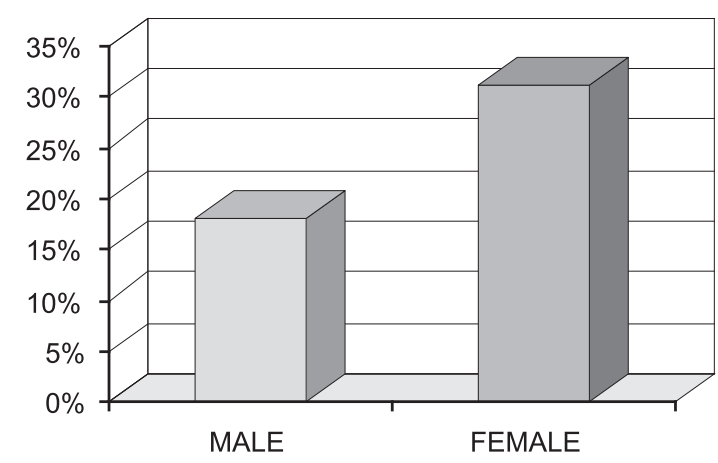

Figure 2.

associations, as for instance- traditional negligence to female in developing countries like Bangladesh.

Another remarkable point that was clear in this study was variation in different levels of morbidity. In male patients, $30.9 \%$ patients had morbidity from 1 week to 1 month; followed by 28.7 $\%$ patients with morbidity less than 1 week, whereas, in case of

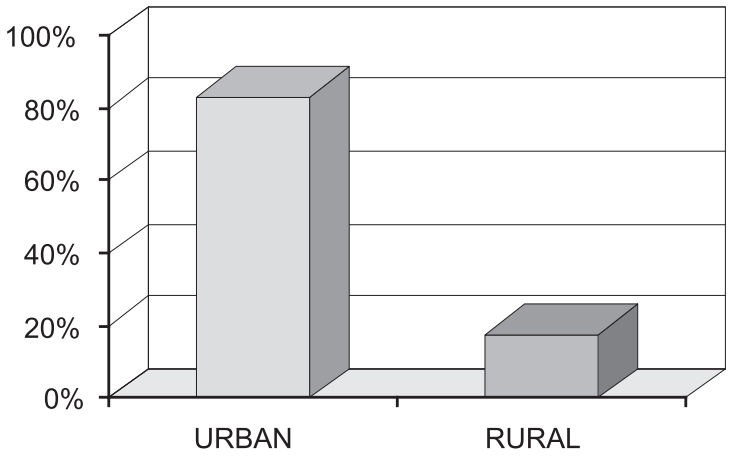

.Fig. 3. Geographic distribution of RTAs.

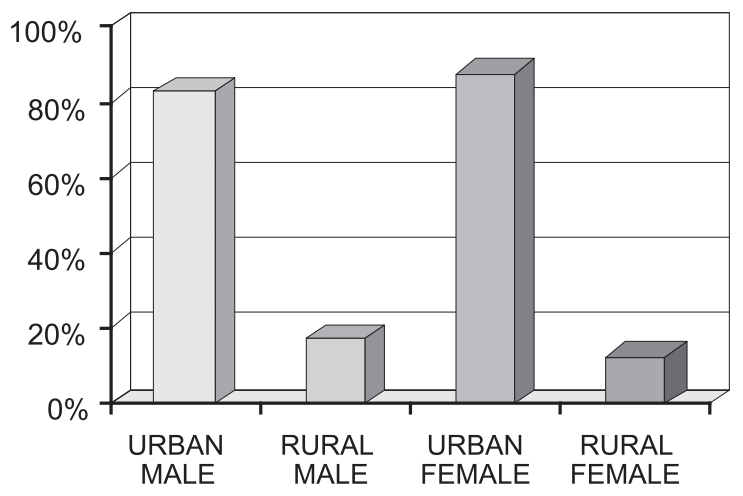

Fig. 4. Geographic distribution in relation to sex.

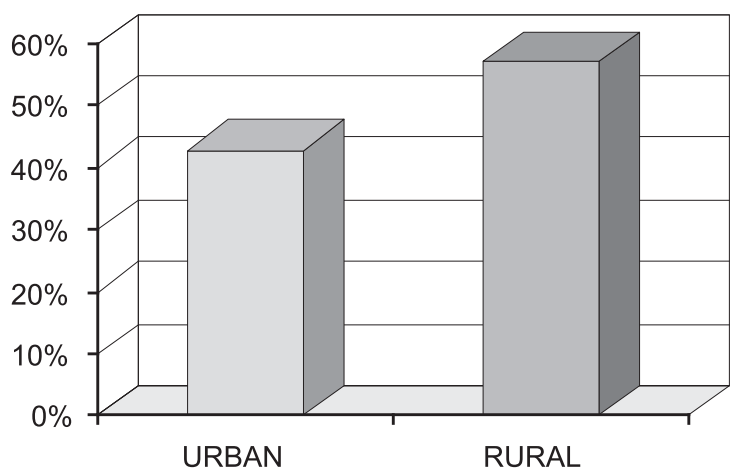

Fig. 5. Geographic distribution of assaults and other homicidal traumas.

females, those were $25.7 \%$ and $20 \%$, respectively. In the question of morbidity over 1 month $23.4 \%$ males and $22.9 \%$ females were found in this group and in case of both male and female, the so called p-values were quite significant (Tab. 2).

Table 3 suggests the most common causes of trauma in both sexes.

So, this study reflects that majority of trauma occurred due to road traffic accidents (RTAs) $(24.5 \%)$ followed by natural disasters $(21.3 \%)$ and assault (17\%) in case of males, whereas, in females $34.3 \%$ trauma occurred by assault and homicidal attempts followed by $20 \%$ due to natural disaster.

Geographic distribution of RTAs and assault are depicted in Figures 3, 4 and 5 . 


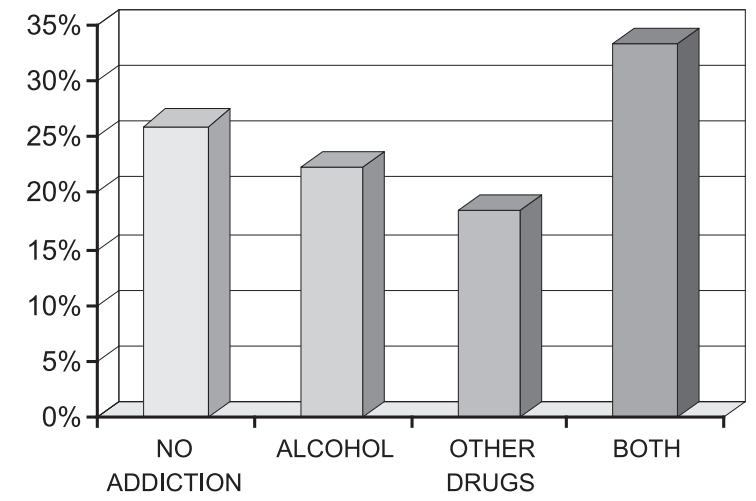

Figure 6.

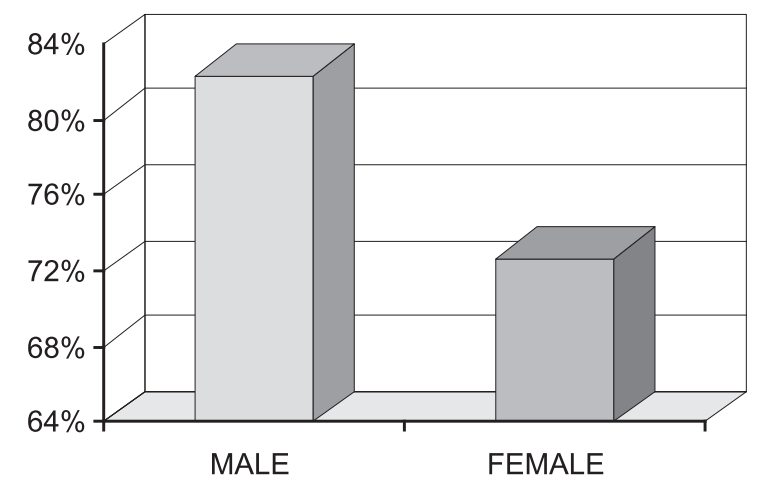

Figure 7.

Some positive associations of RTAs in relation to alcohol and other drug addiction found in this clinical study are shown in Figure 6.

One of the most remarkable associations of traumatic patients was that $82.3 \%$ (28) of all deaths occurred in the first 24 hours of injury in male and $72.7 \%$ (16) in case of female patients. (Fig. 7)

\section{References}

1. Murray CJL, Lopez AD. The Global Burden of Disease. In: Murray CJL, Lopez AD (Eds). Global Burden of Disease and Injury; Vol. 1. The Harvard School of Public Health, 1996.

2. Bourbeau R. Analyse comparative de la mortalite violente dans les pays developpes et dans quelques pays en developpement durant la periode 1985-1989. World Health Statistics Quarterly 1993; 46: 4-32.

3. Trunkey DD. Trauma. Scientific American 1983; 249: 20-78.

4. Murray CJL, Lopez AD. Mortality by cause for eight regions of the world: global burden of disease study. Lancet 1997; 349: 126976.

5. Global socio-economic development trends (1985-1988). World Health Statistics Quarterly 1989; 42: 190-196.

6. Dejevsky M. Gun deaths fall in US - as road toll picks up speed. The Independent, 26th July, 1997: 10.

7. Goodman RA, Istre GR, Jordan FB, Horndon JL, Kelaghan J. Alcohol and fatal injuries in Oklahoma. J Stud Alcohol 1991; 52: 156-161.

8. Levy RS, Hebert CK, Munn BG, Barrack RL. Drug and alcohol use in orthopaedic trauma patients: a prospective study. J Orthop Trauma 1996; 10: 21-27.
9. English S. 'Lollipop' may lick problem of drivers on drugs. The Times, 9th October, 1997.

10. Irwin ST, Patterson CC, Rutherford WH. Association between alcohol consumption and adult pedestrians who sustain injuries in road traffic accidents. Brit Med J 1983; 286: 522.

11. Stinson FS, DeBakey SF. Alcohol-related mortality in the US, 19791988. Brit J Addiction 1992; 87: 777-783.

12. Walsh B, Grant M. International trends in alcohol production and consumption: implications for public health. World Health Statistics Quarterly 1985: 38 : 130-141.

13. HMSO. 1997. International Comparisons of Transport Statistics, 1970-1994. London.

14. HMSO. 1993. Office of Population Censuses and Surveys. Mortality Statistics - Cause. London.

15. Diekstra RFW, Gulbinat W. The epidemiology of suicidal behaviour: a review of three continents. World Health Statistics Quarterly 1993; 46: 52-68.

16. Wolfgang ME. Homicide in other industrialised countries. Bull NY Acad Med 1986; 62: 400-412.

17. World Health Organization, 1976. World Health Statistics Annual, 1973-1976, Geneva.

18. World Health Organization, 1996. World Health Statistics Annual, 1995, Geneva.

19. Waters E, Cliff K. Accidents will happen. Nursing Mirror 1981; 153 : 46-47.

20. Lang-Runtz H. Preventing accidents in the home. Canadian Medical Association Journal 1983; 129: 482-485.

21. Department of Trade and Industry, 1987. Home Accident Surveillance System. Home and Leisure Accident Research: Eleventh Annual Report, London.

22. Poyner B. Home and Leisure Accident Research - The Elderly. London: Department of Trade and Industry, 1986.

23. Mazurek AJ. Epidemiology of paediatric injury. Journal of Accident and Emergency Medicine 1994: 9-16.

24. Poyner B, Hughes N. Home and leisure accident research: personal factors. London: Department of Trade and Industry, 1990.

25. Drever F. Occupational Health Decennial Supplement. London: HMSO, 1995.

26. Lees FP. Loss Prevention in the Process Industries. Oxford: Butterworth-Heinemann, 1996, vol. 1.

27. World Health Organization, 1983. World Health Statistics Annual, 1983, Geneva.

28. World Health Organization, 1995. World Health Statistics Annual, 1994, Geneva.

29. World Health Authority, 1981. World Health Statistics Annual, 1981, Geneva.

30. World Health Authority, 1994. World Health Statistics Annual, 1993, Geneva.

31. Greaves I, Porter KM, Ryan JM. Trauma Care Manual, Oxford University Press, 2001; 8: 1-15.

Received May 29, 2009. Accepted September 20, 2011. 